\title{
The Effect of the Antioxidant Drug “U-74389G" on Haemoglobin Levels Following a Hypoxemia/ Re-oxygenation Protocol in Rats
}

\author{
Constantinos Tsompos ${ }^{1 *}$, Constantinos Panoulis², Konstantinos Toutouzas ${ }^{3}$, George \\ Zografos ${ }^{3}$, Apostolos Papalois 4 \\ 1 Department of Obstetrics \& Gynecology, Mesologi County Hospital, Etoloakarnania, Greece \\ 2 Department of Obstetrics \& Gynecology, Aretaieion Hospital, Athens University, Attiki, Greece \\ 3 Department of Surgery, Ippokrateion General Hospital, Athens University, Attiki, Greece \\ ${ }^{4}$ Experimental Research Center ELPEN Pharmaceuticals, S.A. Inc., Co.
}

\begin{abstract}
Critically ill patients usually present with circulatory hypoxemia and this is associated with a poorer prognosis. The aim of this experimental study was to examine the effect of U-74389G with specific regard to a hypoxemia/re-oxygenation protocol, on mean blood haemoglobin ( $\mathrm{Hgb})$ levels in rats.

Materials and methods: Forty rats (mean weight $231.9 \mathrm{~g}$ ) were used in the study. Hgb levels were measured at sixty minutes (groups A and C) and at 120 minutes (groups B and D) of re-oxygenation. U-74389G was administered only in groups $C$ and $D$.

Results: U-74389G administration non-significantly increased the Hgb levels by $3.95+2.10 \%(p=0.0604)$. Re-oxygenation time non-significantly increased the Hgb levels by $3.39+2.12 \%(p=0.1285)$. U-74389G administration and reoxygenation time together, significantly increased the Hgb levels by $2.55 \%+1.25 \%(p=0.0423)$.

Conclusions: Results of this study indicate that U-74389G administration, re-oxygenation time, but mainly their interaction significantly increase the Hgb levels within the studied time limits.
\end{abstract}

Keywords: hypoxia, haemoglobin, U-74389G, re-oxygenation

Received: 02 May 2015 / Accepted: 05 July 2015

\section{INTRODUCTION}

Circulatory hypoxemia and re-oxygenation (HR) remain the main causes for permanent or transient organ damage, being associated with serious implications concerning the status of the adjacent organs as well as the overall health of the patient. Critically ill patients usually present with circulatory hypoxemia which may contribute to an overall poorer prognosis. A drug with the potential to reverse or restore the hypoxic state would be beneficial to these patients. Although impor- tant progress has been recorded regarding the usage of U-74389G in managing this type of injury, several fundamental questions still remain unanswered, such as the speed of action of this new compound or the recommended dosage or time of administration. The beneficial effect of U-74389G, as an anti-oxidant factor, has been reported in several recent studies [1]. Only few reports have been published concerning U-74389G trials in ischemia reperfusion (IR) studies, mostly providing inadequate conclusions. Additional publications report trials of similar antioxidant molecules

\footnotetext{
Panoulis Constantinos, Department of Obstetrics \& Gynecology, Aretaieion Hospital, 76 Vas. Sofias Ave, Athens 11528, Attiki Greece,

e-mail: Kwn.panoulis@gmail.com

Toutouzas Konstantinos, Department of Surgery, Ippokrateion Hospital, 114 Vas. Sofias Ave, Athens 11527, Attiki Greece,

e-mail: Tousur@hotmail.com

Zografos George, Department of Surgery, Ippokrateion Hospital, 114 Vas. Sofias Ave, Athens 11527, Attiki Greece,

e-mail: Gzografo@med.uoa.gr

Papalois Apostolos, Exprerimental Research Center, ELPEN Pharmaceuticals, S.A. Inc., Co., 95 Marathonos Ave, Pikermi 19009, Attiki Greece, e-mail: Apapalois@elpen.gr

Correspondence to: Tsompos Constantinos, Department of Obstetrics \& Gynecology, Mesologi County Hospital, Nafpaktou street, Mesologi 30200 , Etoloakarnania Greece, e-mail:

constantinostsompos@yahoo.com
} 
belonging to the group which includes U-74389G. U74389G [21-[4-(2,6-di-1-pyrrolidinyl-4-pyrimidinyl)1-piperazinyl]-pregna-1,4,9(11)-triene-3,20-dione maleate salt] is an antioxidant which prevents both arachidonic acid-induced and iron-dependent lipid peroxidation. It has been shown to protect against IR injury in animal heart, liver and kidney models. Membrane-associating antioxidants are particularly effective in preventing permeability changes in brain microvascular endothelial cells monolayers. A meta-analysis of eight published serum variables, coming from the same experimental setting, sought to provide a numeric evaluation of the U-74389G efficacy at the same endpoints (Table 1) [2].

It is hypothesized that the administration of a lipid peroxidation inhibitor lazaroid (U-74389G) will result in an improvement of functional recovery.

The aim of this experimental study was to examine the effect of U-74389G using a rat model and an HR protocol, by measuring blood haemoglobin ( $\mathrm{Hgb}$ ) levels before and after the administration of a lipid peroxidation inhibitor lazaroid (U-74389G).

\section{MATERIAL AND METHODS}

\section{Animal preparation}

Ethical approval and the appropriate licence was obtained from the Veterinary Department of the East Attiki Prefecture [Licence: 3693/12-11-2010 \& 14/101-2012]. All settings needed for the study including consumables, equipment and substances used, were a courtesy of Exprerimental Research Center of ELPEN Pharmaceuticals Co. Inc. S.A. at Pikermi, Attiki. Accepted standards of humane animal care for female Albino Wistar rats were followed and conformed to the guiding principles of the Declaration of Helsinki. The animals were housed in the laboratory for seven days before the experiment commenced where a continuous supply of water and food was available.

\section{Study groups and X HR injury model}

The study was carried out on forty female Wistar albino rats aged 16-18 weeks old having a mean weight (SD) of 231.9 (36.6) g, with minimum weight $\geq 165 \mathrm{~g}$ and max weight $<320 \mathrm{~g}$. The rats were randomly allocated to four groups $(\mathrm{No}=10)$.

\section{Control Groups}

The control group comprised twenty rats, mean (SD) weight of 252.5 (39.3) g, and was subdivided into two groups $A(n=10)$ and $B(n=10)$

In Group A and B, hypoxia was induced for forty five minutes followed by re-oxygenation for sixty minutes (group A) and for forty five minutes followed by reoxygenation for 120 minutes (group B) (Table 2).

\section{Experimental Groups}

The experimental group comprised twenty rats, mean (SD) weight of 252.5 (39.3) g, and was subdivided into two groups $\mathrm{C}(\mathrm{n}=10)$ and $\mathrm{D}(\mathrm{n}=10)$

In Group $\mathrm{C}$ and $\mathrm{D}$, hypoxia was induced for forty five minutes followed immediate by U-74389G intravenous (IV) administration and re-oxygenation for sixty minutes (group C) and for forty five minutes followed immediate by U-74389G IV administration and reoxygenation for 120 minutes (table 2). The dosage of $\mathrm{U}-74389 \mathrm{G}$ was $10 \mathrm{mg} / \mathrm{Kg}$ of the animals' mass.

\section{Anaesthetic procedure \& induction of hypoxia and re-oxygenation procedure}

All rats were anesthetised using a pre-narcosis regime followed by general anaesthesia. The detailed anesthesiologic technique is described in related references 2.

Table 1. The U-74389G influence mean (+SD) on the levels of some serum variables associated with reperfusion time

\begin{tabular}{|c|c|c|c|c|c|c|c|c|}
\hline Variable & 1h rep* & p-value & $1.5 \mathrm{~h}$ rep & p-value & $2 \mathrm{~h}$ rep & p-value & $\begin{array}{l}\text { interaction of } \mathrm{U} \text { - } \\
74389 \mathrm{G} \text { and rep }\end{array}$ & p-value \\
\hline RBC & $+1.39 \%+0.71 \%$ & 0.7161 & $+0.64 \%+0.32 \%$ & 0.8106 & $-0.10 \%+0.05 \%$ & 0.9762 & $+1.05 \%+0.53 \%$ & 0.4911 \\
\hline glucose & $-6.41 \%+3.50 \%$ & 0.0663 & $-8.57 \%+2.06 \%$ & 0.0001 & $-10.74 \%+2.52 \%$ & 0.0003 & $-4.76 \%+1.28 \%$ & 0.0005 \\
\hline total protein & $-5.48 \%+2.99 \%$ & 0.0663 & $-7.34 \%+1.76 \%$ & 0.0000 & $-9.20 \%+2.16 \%$ & 0.0000 & $-4.08 \%+1.10 \%$ & 0.0000 \\
\hline $\begin{array}{l}\text { alkaline } \\
\text { phosphatase }\end{array}$ & $+22.66 \%+12.37 \%$ & 0.0663 & +31.91\%+7.69\% & 0.0001 & $+41.16 \%+9.65 \%$ & 0.0003 & $+17.75 \%+4.79 \%$ & 0.0005 \\
\hline sodium & $+1.22 \%+0.66 \%$ & 0.0707 & $+0.17 \%+0.61 \%$ & 0.7714 & $-0.87 \%+1.03 \%$ & 0.3995 & $-0.32 \%+0.36 \%$ & 0.3693 \\
\hline chloride & $-0.58 \%+0.77 \%$ & 0.4533 & $-0.97 \%+0.53 \%$ & 0.0879 & $-1.36 \%+0.76 \%$ & 0.1113 & $-0.75 \%+0.38 \%$ & 0.0159 \\
\hline calcium & $0 \%+1.75 \%$ & 01/01/00 & $-0.14 \%+1.10 \%$ & 0.8782 & $-0.28 \%+1.54 \%$ & 0.8492 & $+0.14 \%+0.64 \%$ & 0.8245 \\
\hline phosphorus & $-2.23 \%+5.51 \%$ & 0.7966 & $-1.61 \%+3.32 \%$ & 0.5789 & $-1 \%+4.48 \%$ & 0.8129 & $-1.09 \%+2 \%$ & 0.5771 \\
\hline mean & $+1.32 \%+9.09 \%$ & 0.4044 & $+1.76 \%+12.67 \%$ & 0.3909 & $+2.20 \%+16.29 \%$ & 0.3937 & $+0.99 \%+7.06 \%$ & 0.2848 \\
\hline
\end{tabular}


Oxygen supply, electrocardiogram and acidimetry were continuously provided during the procedure. Sampling was carried out following vena cava venipuncture by filling a 2cc dimpled control stroke syringe with a preset volume for withdrawal and sterile insulin needle. Then, the sample was transferred to a vacuum blood collection tube (disposable vacutainer) of $2 \mathrm{cc}$, containing K2EDTA, the "anticoagulant of choice in specimen collection and haemoglobin counting" according to both NCCLS and the International Council for Standardization in Haematology. Haemoglobin level measurements were performed using a Nihon Kohden celltac a MEK-6450 K automatic haematology analyser with pre-set rat type and cyanide-free reagents.

Hypoxia was initiated by clamping the inferior aorta above the level of the renal arteries with forceps, for a period of forty five minutes. Re-oxygenation was induced by removing the forceps clamp allowing re-establishment of the patency of the vessel.

$\mathrm{U}-74389 \mathrm{G}$ was administered at the time of re-oxygenation via the inferior vena cava following catheterization. The Hgb levels measurements were performed at sixty minutes post re-oxygenation (groups $\mathrm{A}$ and $\mathrm{C}$ ) and at 120 minutes post re-oxygenation (groups $\mathrm{B}$ and $\mathrm{D}$ ).

\section{Statistical analysis}

The statistical tests used were successive paired t-tests and generalized linear models, using the STATA 6.0 statistical software. The combined weight of each group of rats was compared with that of each of the three other groups, using the paired t-test (Table 3 ).

\section{DESULTS}

Applying generalized linear models, with Hgb levels as the dependent variable, and U-74389G administration or no U-74389G administration, re-oxygenation time and their interaction as the independent variables, it was observed that U-74389G administration non-significantly increased the Hgb levels by $0.57 \mathrm{~g} / \mathrm{dl}[-0.02$ $\mathrm{g} / \mathrm{dl}$ to $1.16 \mathrm{~g} / \mathrm{dl}](\mathrm{p}=0.0595)$. This finding was in accordance with the results of paired t-test $(p=0.0613)$. Re-oxygenation time was not significantly associated with an increase in $\mathrm{Hgb}$ levels by $0.49 \mathrm{~g} / \mathrm{dl}[-0.11 \mathrm{~g} / \mathrm{dl}$ to $1.09 \mathrm{~g} / \mathrm{dl}](\mathrm{p}=0.1075)$, also in accordance with paired t-test $(\mathrm{P}=0.1495)$. However, U-74389G administration and re-oxygenation time together were significantly associated with an increase in the Hgb levels by $0.37 \mathrm{~g} / \mathrm{dl}$ $[0.01 \mathrm{~g} / \mathrm{dl}$ to $0.72 \mathrm{~g} / \mathrm{dl}](\mathrm{p}=0.0423)$.
Table 2. Weight and mean haemoglobin mean values of groups

\begin{tabular}{cccc} 
Groups & Variable & Mean & Std. Dev \\
\multirow{2}{*}{ A } & Weight & $243 \mathrm{~g}$ & $45.77 \mathrm{~g}$ \\
& Haemoglobin & $13.86 \mathrm{~g} / \mathrm{dl}$ & $0.87 \mathrm{~g} / \mathrm{dl}$ \\
\hline \multirow{2}{*}{ B } & Weight & $262 \mathrm{~g}$ & $31.10 \mathrm{~g}$ \\
& Haemoglobin & $14.52 \mathrm{~g} / \mathrm{dl}$ & $1.11 \mathrm{~g} / \mathrm{dl}$ \\
\hline \multirow{2}{*}{ C } & Weight & $212.5 \mathrm{~g}$ & $17.83 \mathrm{~g}$ \\
& Haemoglobin & $14.6 \mathrm{~g} / \mathrm{dl}$ & $0.80 \mathrm{~g} / \mathrm{dl}$ \\
\hline \multirow{2}{*}{ D } & Weight & $210 \mathrm{~g}$ & $18.10 \mathrm{~g}$ \\
& Haemoglobin & $14.92 \mathrm{~g} / \mathrm{dl}$ & $0.82 \mathrm{~g} / \mathrm{dl}$ \\
\hline
\end{tabular}

Table 3. Statistical significance of mean values difference for groups (DG) after statistical paired t test application

\begin{tabular}{cccc} 
DG & Variable & Difference & p-value \\
A-B & Weight & $-19 \mathrm{~g}$ & 0.2423 \\
& Haemoglobin & $-0.66 \mathrm{~g} / \mathrm{dl}$ & 0.2422 \\
\hline A-C & Weight & $30.5 \mathrm{~g}$ & 0.0674 \\
& Haemoglobin & $-0.74 \mathrm{~g} / \mathrm{dl}$ & 0.1204 \\
\hline A-D & Weight & $33 \mathrm{~g}$ & 0.0574 \\
& Haemoglobin & $-1.06 \mathrm{~g} / \mathrm{dl}$ & 0.0255 \\
\hline B-C & Weight & $49.5 \mathrm{~g}$ & 0.0019 \\
& Haemoglobin & $-0.07 \mathrm{~g} / \mathrm{dl}$ & 0.8638 \\
\hline B-D & Weight & $52 \mathrm{~g}$ & 0.0004 \\
& Haemoglobin & $-0.39 \mathrm{~g} / \mathrm{dl}$ & 0.3350 \\
\hline C-D & Weight & $2.5 \mathrm{~g}$ & 0.7043 \\
& Haemoglobin & $-0.31 \mathrm{~g} / \mathrm{dl}$ & 0.4509 \\
\hline
\end{tabular}

Table 3 gives the statistical significance of mean values difference for groups. [paired $t$ test]

Table 4 shows the increasing influence of U-74389G in connection with re-perfusion time.

Table 5 shows the (\%) increasing influence of U$74389 \mathrm{G}$ in connection with re-perfusion time

\section{DISCUSSION}

These observations indicate an increasing effect of U-74389G administration with respect to reperfusion time. Because a more obese rat usually presents higher Hgb levels, the notion that a rat's weight could potentially be a confounding factor was also investigated. The weight of each rat was compared with the others (Table 3). However, including the rats' weights as an independent variable using generalized linear models analysis, produced a non-significant relationship ( $\mathrm{p}=0.5367)$, with no further investigation being required.

The following clinical situations show not only how hypoxemia influences the Hgb levels, but also the reverse influence. Barshishat-Kupper et al found that 
Table 4. The increasing influence of U-74389G in connection with reperfusion time

\begin{tabular}{ccccc} 
Change & 95\% c. in. & Reperfusion time & p-values & glm \\
$0.74 \mathrm{~g} / \mathrm{dl}$ & $-0.04 \mathrm{~g} / \mathrm{dl}-1.52 \mathrm{~g} / \mathrm{dl}$ & $1 \mathrm{~h}$ & 0.1204 & 0.0647 \\
$0.56 \mathrm{~g} / \mathrm{dl}$ & $-0.02 \mathrm{~g} / \mathrm{dl}-1.16 \mathrm{~g} / \mathrm{dl}$ & $1.5 \mathrm{~h}$ & 0.0613 & 0.0595 \\
$0.39 \mathrm{~g} / \mathrm{dl}$ & $-0.52 \mathrm{~g} / \mathrm{dl}-1.32 \mathrm{~g} / \mathrm{dl}$ & $2 \mathrm{~h}$ & 0.3350 & 0.3738 \\
$0.49 \mathrm{~g} / \mathrm{dl}$ & $-0.11 \mathrm{~g} / \mathrm{dl}-1.09 \mathrm{~g} / \mathrm{dl}$ & re-oxygenation time & 0.1495 & 0.1075 \\
$0.36 \mathrm{~g} / \mathrm{dl}$ & $0.01 \mathrm{~g} / \mathrm{dl}-0.72 \mathrm{~g} / \mathrm{dl}$ & interaction & 0.0423 \\
\hline
\end{tabular}

Table 5. The (\%) increasing influence of U-74389G in connection with reperfusion time

\begin{tabular}{cccc} 
Increase & +SD & Reperfusion time & p-value \\
$+5.2 \%$ & $+2.8 \%$ & $1 \mathrm{~h}$ & 0.0925 \\
$+3.9 \%$ & $+2.1 \%$ & $1.5 \mathrm{~h}$ & 0.0604 \\
$+2.7 \%$ & $+3.2 \%$ & $2 \mathrm{~h}$ & 0.3544 \\
$+3.5 \%$ & $+2.1 \%$ & re-oxygenation time & 0.1285 \\
$+2.5 \%$ & $+1.3 \%$ & interaction & 0.0423 \\
\hline
\end{tabular}

short-term erythroid progenitors suppression after total body irradiation is favourable for erythroid recovery by erythropoietin (Epo) administration in mice [3]. Weltert L. et al recorded that patients with isolated coronary vessel disease required blood units on postoperative day four [4]. Gardin C. et al had to transfuse myelodysplastic syndrome patients [5]. Ferber A. et al did not detect a rise in umbilical cord plasma Epo levels until four to six hours after hypoxia initiation. The neonatal RBC (NRBC) counts were elevated in foetuses who were delivered for "non-reassuring foetal status (acute hypoxia)" than controls, with Epo levels being normal in both groups [6]. Fujishiro N. et al studied the long-term response of mammals to hypoxia with consequent increase in RBC counts [7]. Vatansever U. et al found a significant difference in terms of NRBC counts $(\mathrm{p}=0.038)$ in neonates' circulation associated with states of relative hypoxia [8]. Singbartl G. et al studied end-stage renal failure patients anaemia reversal and their preoperative donated either autologous or homologous blood volume transfused increase [9]. Hara $\mathrm{H}$. et al indicated that the serial changes in the number of erythropoietic burst-forming units (BFU-E) represent migration of BFU-E from marrow to spleen rather than $\mathrm{BFU}-\mathrm{E}$ proliferation since the transient decline in the femoral BFU-E coincided with the temporary increase in the splenic and blood BFU-E. Marrow erythrocyte colony-forming units (CFU-E) were increased in anaemic mice and decreased in polycythaemic mice without changes in their proliferative state [10]. All the above situations show that anaemia and hypoxemia independently of the reason, cause a retarded haematopoiesis mobilizing Epo. A factor favouring acute haemopoiesis before Epo takes effect, may prove interesting.

There remains a current undiminished interest in the identification of new drugs that could improve the status of critically ill patients, by correcting the hypoxemia-re-oxygenation distress. The antioxidants such as lazaroids. U-74389G belongs to this chemical family. Reports of the effect of U-74389G on Hgb levels are few to date. Haddad et al [11], in a study performed on guinea pigs, demonstrated that lipid peroxidation is increased in acute otitis media, indicating a potential role that free radicals could play as contributors to inflammation. In conditions of elevated systemic inflammatory, free radicals could participate in the development of several diseases. Lipid peroxides such as malondialdehyde are nowadays considered markers of cell membrane damage associated with oxidative stresses. In their study [11], they examined the effect of lazaroid U-74389G, a 21-aminosteroid, on acute otitis media in guinea pigs, after the right tympanic cavity was inoculated with Streptococcus pneumoniae organisms while sterilized phosphate-buffered saline solution was injected into the left ear to serve as a control. Every twelve hours, the guinea pigs were given intraperitoneal injections of $40 \mathrm{mg} / \mathrm{kg}$ of a lazaroid compound or its vehicle. Middle ear mucosa was collected and used for assay. Lipid peroxide was quantified using the methylene blue-hgb method and acid reactive substance measurement. The authors found that injection of Lazaroid significantly suppressed production of lipid hydroperoxide of the middle ear mucosa of the guinea pigs with acute otitis media for up to 24 hours ( $p<0.05)$, suggesting that lazaroid may reduce lipoperoxidation in the middle ear at an early stage of acute otitis media [11]. 


\section{CONCLUSION}

The present study indicates that U-74389G administration, re-oxygenation time, but mainly their interaction significantly increase Hgb levels within the stated time periods. A longer study time might provide more information of a clinically relevant nature.

\section{口ACKNOWLEDGMENT}

This study was funded by Scholarship by the Experimental Research Center ELPEN Pharmaceuticals (E.R.C.E), Athens, Greece. The research facilities for this project were provided by the aforementioned institution.

\section{REFERENCES}

1. Shi F, Cavitt J, Audus KL. 21-aminosteroid and 2-(aminomethyl) chromans inhibition of arachidonic acid-induced lipid peroxidation and permeability enhancement in bovine brain microvessel endothelial cell monolayers. Free Radic Biol Med. 1995;19:349-57.

2. Tsompos C, Panoulis C, Toutouzas K, Zografos G, Papalois A. The Hypoglucemic Effect of the Antioxidant Drug "U-74389g" during Ischemia Reperfusion Injury in Rats. Int J Diabetes Clin Res. 2015;2:1-4.

3. Barshishat-Kupper M, Mungunsukh O, Tipton AJ, et al. Captopril modulates hypoxia inducible factors and erythropoietin responses in a murine model of total body irradiation. Exp Hematol. 2011;39:293-304.

4. Weltert L, D'Alessandro S, Nardella S, et al. Preoperative very short-term, high-dose erythropoietin administration diminishes blood transfusion rate in off-pump coronary artery bypass: a randomized blind controlled study. J Thorac Cardiovasc Surg. 2010;139:621-7.

5. Gardin C, Fenaux P. Supportive care including growth factors in myelodysplastic syndromes. Rev Clin Exp Hematol. 2004;8:E3.

6. Ferber A, Minior VK, Bornstein E, et al. Fetal "nonreassuring status" is associated with elevation of nucleated red blood cell counts and interleukin-6. Am J Obstet Gynecol. 200;192:14279.

7. Fujishiro N, Endo $Y$, Warashina A, et al. Mechanisms for hypoxia detection in O2-sensitive cells. Jpn J Physiol. 2004;54:109-23.

8. Vatansever $U$, Acunaş B, Demir M, et al. Nucleated red blood cell counts and erythropoietin levels in high-risk neonates. Pediatr Int. 2002;44:590-5.

9. Singbartl G. Adverse events of erythropoietin in long-term and in acute/short-term treatment. Clin Investig. 1994;72(6 Suppl):S36-43.

10. Hara H, Ogawa M. Erythropoietic precursors in mice under erythropoietic stimulation and suppression. Exp Hematol. 1977;5:141-8.

11. Haddad J Jr, Egusa K, Takoudes TG. Effects of 21-aminosteroid U-74389G on acute otitis media in a guinea pig model. Otolaryngol Head Neck Surg. 1998;118:44-8. 